\title{
Arachnoid cysts in a brother and sister
}

\author{
WILLIAM G WILSON*, KATHLEEN A DEPONTE†, \\ JOAN McILHENNY*, AND F E DREIFUSS* \\ ${ }^{*}$ Departments of Pediatrics, Radiology, and Neurology, University of Virginia Medical Center, Charlottesville; \\ and the Department of Radiology, St Mary's Hospital, Norton, Virginia, USA.
}

SUMMARY We describe a brother and sister with microcephaly and mental retardation who were shown by cranial CT scan to have almost identical unilateral arachnoid cysts. The occurrence in sibs suggests the possibility of a genetic basis for at least some cases of arachnoid cysts.

Arachnoid cysts are extraparenchymal, nonneoplastic accumulations of fluid with density similar to CSF. ${ }^{1}$ It has been estimated that they account for $1 \%$ of intracranial space occupying lesions, ${ }^{2}$ although more recent studies (since the advent of CT scanning) suggest that this percentage might be as high as $4 \cdot 8 \% .{ }^{3} \mathrm{~A}$ striking male predominance has been observed in published series. ${ }^{23}$ There have been few reports of familial arachnoid cysts. We report a brother and sister with microcephaly and mental retardation who were found on CT scan to have almost identical arachnoid cysts.

\section{Case reports}

Case 1 , a female now aged 16 years, was the $2.8 \mathrm{~kg}$ product of an uncomplicated pregnancy. Her early developmental milestones were normal until 18 months of age, when delay in speech prompted a medical evaluation. At the age of nine years, she began having seizures which were described as episodes of staring, occasionally falling, and making strange noises. These episodes lasted one to two minutes and were well controlled by phenobarbital and phenytoin. At the age of 15 years, her height and weight were on the 25th and 50th centiles, respectively, while her head circumference $(50 \mathrm{~cm})$ was less than the 2nd centile for age. Except for microcephaly, a sloping forehead, and increased deep tendon reflexes in the lower extremities, her physical examination was unremarkable. No abnormal skin lesions were present. She was able to converse, but her speech seemed fragmented and erratic.

Received for publication 8 October 1987

Accepted for publication 13 November 1987.
Case 2 , the brother of case 1 , is now aged 14 years. He was the $2.6 \mathrm{~kg}$ product of a prolonged labour following an uncomplicated pregnancy. Microcephaly was noted in early infancy. His early motor milestones were normal, but he did not walk alone until the age of 23 months. His language development has been severely delayed and he speaks few words; his receptive language is also superior to his expressive language. He has generalised grand mal seizures with upward movement of his eyes, occurring about twice monthly, usually during sleep. At the age of 14 years, his height and weight were on the 25th and 60th centiles for age, respectively, while his head circumference $(50 \mathrm{~cm})$ was below the 2 nd centile. $\mathrm{He}$ was obviously microcephalic, with posterior sloping of the forehead, relative prominence of the supraorbital ridges, and mild synophrys. He had four small hyperpigmented macules but no Lisch nodules, axillary freckles, or other skin lesions of neurofibromatosis. His physical examination was otherwise unremarkable with the exception of the neurological examination. The deep tendon reflexes were increased and bilateral extensor plantar responses were noted. There was mild contracture of the right ankle with clonus. No other lateralising signs were noted.

Neither patient had a history of birth trauma or CNS infection. Both patients have had normal urinary quantitative amino acid analyses and urine tests with ferric chloride, dinitrophenylhydrazine, and cetylpyridinium chloride. A banded lymphocyte karyotype performed on case 2 was normal.

The parents of these children are 31 years of age and are of apparently normal intelligence. Although there is no known consanguinity, the families of both parents live in the same relatively small region, and several common surnames occur in the pedigree. The mother's head circumference is $53 \mathrm{~cm}$ (20th centile); the father is not available. There are no relatives with obvious mental retardation, seizures, or skin lesions.

CT scan of case 1 at 14 years of age and case 2 at 12 years revealed strikingly similar cysts in the posterior left hemisphere, extending inferiorly from the cerebral convexity to the middle cranial fossa and posterior fossa (figure). There was no obvious 

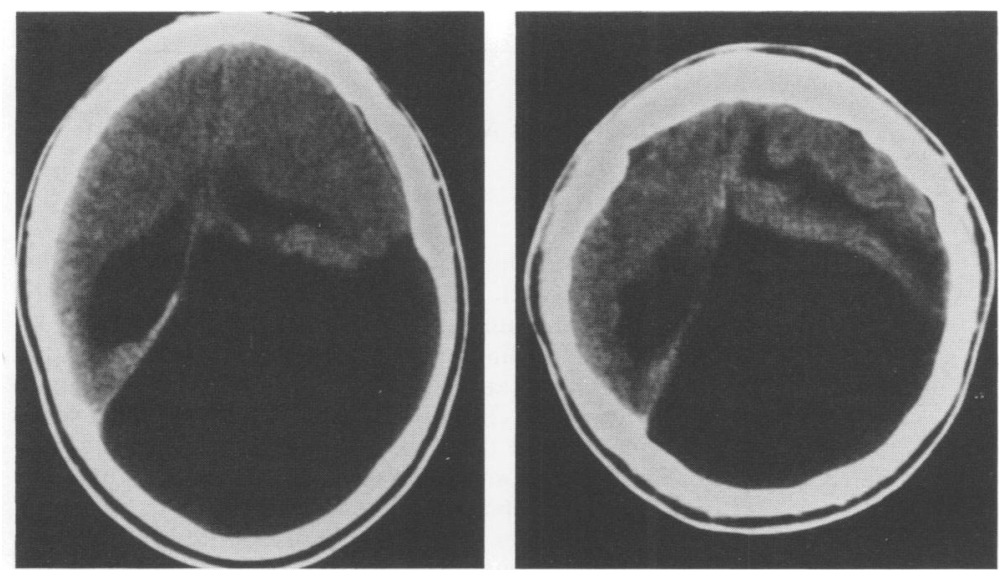

FIGURE Representative image from cranial CT scan from case 1 (left) and case 2 (right). Note the similarity in appearance of the cysts, the erosion of the inner table of the skull, and the eccentric placement of the falx.

communication with the ventricles. The left temporal lobe and left hemisphere were displaced anteriorly. The cerebellum and fourth ventricle were shifted to the right. The corpus callosum could not be clearly identified. Erosion of the inner table of the skull and the eccentric position of the falx suggested long standing mass effect. Enlargement of the temporal horns of the right lateral ventricle was also noted. The findings in case 2 differed only in that the cyst was less prominent in the posterior fossa.

\section{Discussion}

Although arachnoid cysts are relatively common findings on CT scan, the cause of these cysts is not certain. There are two theories regarding their pathogenesis. One is that the cysts arise because of fluid accumulation between the layers of arachnoid, with secondary underdevelopment of the brain owing to pressure. ${ }^{3}$ The second theory is that the cysts arise after hypoplasia of the cerebrum, making the cysts secondary phenomena. ${ }^{2} \mathrm{~A}$ wide range of neurological findings have been described in patients with arachnoid cysts; some patients are asymptomatic.

It is likely that arachnoid cysts are aetiologically heterogeneous. Some have been found following trauma, while others are apparently congenital. The familial occurrence of arachnoid cysts is uncommon. We are aware of two previous reports of familial arachnoid cysts. Handa $e t$ al ${ }^{4}$ reported two brothers, aged 10 months and three years, with macrocrania and bilateral arachnoid cysts in the middle cranial fossa. The younger brother was developmentally normal and had transient hyperreflexia on the left, while the older child was developmentally delayed and had persistent left hemiparesis. These authors cited a report by Kuzuhara et al describing two brothers, age five and three years, with macrocrania and bilateral arachnoid cysts. ${ }^{4}$

The patients whom we describe presented with microcephaly (not macrocrania) and developmental delay and have no striking lateralising findings on clinical examination. The presence of similar CT findings in both the male and female sib is evidence against an $\mathrm{X}$ linked or sex influenced aetiology. The occurrence of these cysts in sibs does suggest a genetic basis for at least some cases of this condition, although statements regarding the mode of inheritance based on the limited number of reports of familial cases would be premature. The available reports are compatible with an autosomal recessive or multifactorial pattern of inheritance. Further delineation of the genetic mechanism involved must await additional reports and family studies.

\section{References}

${ }^{1}$ Latchaw RE, ed. Computed tomography of the head, neck, and spine. Chicago: Year Book Medical Publishers, 1985.

2 Robinson RG. Congenital cysts of the brain: arachnoid malformation. Prog Neurol Surg 1971;4:133-74.

3 Galassi EM Piazza G, Gaist G, Frank F. Arachnoid cysts of the middle cranial fóssa: a clinical and radiological study of 25 cases treated surgically. Surg Neurol 1980;14:211-9.

${ }^{4}$ Handa J, Okamoto K, Sato M. Arachnoid cyst of the middle cranial fossa: report of bilateral cysts in siblings. Surg Neurol 1981;16:127-30.

Correspondence and requests for reprints to $\mathrm{Dr}$ William G Wilson, Department of Pediatrics, University of Virginia Medical Center, Charlottesville, Virginia 22908, USA. 